\title{
Improving the care of inpatients who are homeless: why we need to ask 'have you got somewhere safe to go when you leave hospital?' and use the Homelessness Reduction Act 2017 'duty to refer' process
}

\author{
Authors: Esme Ingram, ${ }^{A}$ Hannah Karet, ${ }^{A}$ Sarah Simons, ${ }^{A}$ Gill Taylor, ${ }^{B}$ Karen Lucas ${ }^{C}$ and Louise Restrick ${ }^{A}$
}

\begin{abstract}
Introduction
'Homelessness' is an increasingly important UK healthcare issue. Mean age of death of people who are homeless is 43-47 years and there were 726 homeless deaths in England and Wales in 2018., People who are homeless have complex health needs reflected in increasing emergency attendances and admissions. ${ }^{1}$ One in three deaths might have been preventable with timely treatment, yet 'homelessness' is often not identified by clinicians as a health issue and is poorly documented in health records., ${ }^{1,3}$

The Homelessness Reduction Act (HRA) 2017, ${ }^{4}$ which came into place in October 2018, imposes a legal duty on NHS trusts to refer people experiencing / at risk of homelessness to 'their' local authority (LA) housing team for needs assessment, subject to their consent ('duty to refer' (DtR)).

The aim of this audit was to investigate the prevalence and characteristics/needs of inpatients who are 'homeless' in one innercity hospital, and to evaluate the use of DtR.
\end{abstract}

\section{Materials and methods}

A snapshot audit of 'homelessness' in an inner-city hospital was performed by a team of trainee doctors, in partnership with two LA housing teams, in July 2019. All adult inpatients were asked 'have you got somewhere safe to go when you leave hospital?'

With their consent, those identified as 'homeless' answered further questions about their current situation and information on demographics / diagnoses / length of stay (LOS) was anonymously extracted from their records. They were offered a meeting with a housing specialist on the ward and that the DtR process be completed by their ward team.

\section{Results and discussion}

In total, 204 adult inpatients were interviewed; 70 (34\%) were unable to answer, predominantly due to cognitive impairment $(n=42)$.

Authors: ${ }^{A}$ Whittington Health NHS Trust, London, UK; ${ }^{B}$ Haringey Local Authority, London, UK; C Islington Local Authority, London, UK
Fifteen ( 10 male; five female) patients ( $7 \%$ total and $11 \%$ of those able to participate) were identified as not having somewhere safe to go. All 15 agreed to further review; mean (range) age was 57 (40-72) years. Comorbidities are shown in Table 1; mean (range) comorbidities was six (1-15); Mean (range) LOS was 36 (5-199) days and 6/15 (40\%) did not have a working mobile phone; 10/15 (66\%) were 'sofa surfing'; none had been referred using DtR and for $3 / 15$ (20\%) their team was unaware they were 'homeless'; $8 / 15$ met a housing specialist and all eight had DtR completed.

\section{Conclusion}

Eleven per cent of adult inpatients in an inner-city hospital were identified as 'homeless' during this summer 2019 snapshot audit. As expected, ${ }^{1}$ these patients had multiple physical and mental

Table 1. Documented prevalence of common underlying long-term conditions for group of inpatients in an acute trust $(n=15)$ identified as being homeless or at risk of homelessness

$\begin{array}{ll}\text { Comorbidity } & \text { Prevalence } \mathbf{n} \text { (\%) } \\ \text { Mental health diagnosis } & 5(33) \\ \text { Tobacco dependence (current/previous) } & 9(60) \\ \text { Alcohol dependence (current/previous) } & 8(53) \\ \text { Other substance misuse (current/ } & 4(27) \\ \text { previous) } & \\ \text { Respiratory disease } & 8(53) \\ \text { Cognitive impairment/dementia } & 2(13) \\ \text { Obesity } & 3(20) \\ \text { Cardiovascular disease } & 5(33) \\ \text { Type 2 diabetes mellitus } & 4(27) \\ \text { Leg ulcers / cellulitis / pressure sores } & 2(13) \\ \text { Liver disease } & 2(13) \\ \text { Epilepsy } & 1(7) \\ \text { Cancer } & 2(13) \\ \text { Venous thromboembolism } & 1(7)\end{array}$


health comorbidities and 'long' hospital admissions. Teams were unaware that homelessness was an issue for one in five who were 'homeless', and none had previously been referred using DtR.

To address these, and other gaps, in our care of this high-cost, high-needs group, we now have a trust-wide Homelessness Quality Improvement Group, working in partnership with two LA housing teams. $^{5}$

Initial aims have been to:

> Start to embed 'Have you got somewhere safe to go when you leave hospital?' as a standard healthcare question asked by clinicians of all patients presenting to our hospital.

$>$ Make it easier for clinicians to document 'homelessness' as a 'diagnosis' in a patient's health record.

> Make it easier for clinicians to complete 'DtR' for patients identified as homeless, who consent to referral, by using an electronic pathway within our health record, so their housing needs can be assessed/addressed by the appropriate LA housing team

\section{Conflicts of interest}

None declared.

\section{References}

1 Public Health England. Health matters: rough sleeping. GOV.UK, 2020. www.gov.uk/government/publications/health-matters-roughsleeping/health-matters-rough-sleeping.

2 Office for National Statistics. Deaths of homeless people in England and Wales: 2018. ONS, 2019. www.ons.gov.uk/ peoplepopulationandcommunity/birthsdeathsandmarriages/ deaths/bulletins/deathsofhomelesspeopleinenglandandwales/2018 [Accessed 20 October 2019].

3 Jacob R. Preventing homelessness: it's everybody's business. Crisis, 2018. www.crisis.org.uk/media/239551/preventing_homelessness_ its_everybodys_buisness_2018.pdf [Accessed 20 October 2019].

4 Ministry of Housing, Communities \& Local Government. Homelessness: duty to refer. GOV.UK, 2018. www.gov.uk/government/publications/ homelessness-duty-to-refer [Accessed 20 October 2019].

5 Blumenthal D, Chernof B, Fulmer T, Lumpkin J, Selberg J. Caring for high-need, high-cost patients - an urgent prioroty. N Engl J Med 2016;375:909-11. 